\title{
IONIC CONDUCTIVITY IN LAYER SILICATES CONTROLLED BY INTERCALATION OF MACROCYCLIC AND POLYMERIC OXYETHYLENE COMPOUNDS
}

\author{
P. Aranda, ${ }^{*}$ J. C. Galvan, $†$ B. Casal* and E. Ruiz-Hitzky* $¥$ \\ "Instituto de Ciencia de Materiales, C.S.I.C., C/ Serrano 115-bis 28006 Madrid, Spain \\ †Centro Nacional de Investigaciones Metalúrgicas, C.S.I.C. Avda. Gregorio del Amo 8, \\ 28040 Madrid, Spain
}

(Received 20 December 1991)

\begin{abstract}
This contribution concerns intercalation materials based on the formation of intracrystalline polymer-salt complexes obtained by insertion of poly(ethylene oxide) (PEO) and crown-ether compounds in a layer silicate (montmorillonite), containing $\mathrm{Na}^{+}$exchangeable cations in their interlayer space. Polyoxyethylene compounds (crown ethers and PEO) are able to associate interlayer cations modifying dramatically the ionic conductivity of the natural silicate. The new organo-inorganic materials exhibit a two-dimensional structure able to induce an anisotropic character in their electrical properties.
\end{abstract}

Key words: crown-ethers, PEO, montmorillonite, intercalation, impedance spectroscopy.

\section{INTRODUCTION}

Some natural silicates belonging to the $2: 1$ charged phyllosilicates family, eg montmorillonite, are built up by the stacking of negatively charged layers composed of two tetrahedral silica sheets and a central octahedral magnesium and aluminium sheet, which are compensated by cations in the interlayer region. These cations, which are usually hydrated, can be easily exchanged by treatments with saline solutions giving homoionic samples. Interlayer water molecules associated to cations exhibit acidic character[1] and consequently these hydrated materials show protonic conductivity[2]. The layered structure imposes an anisotropic behaviour regarding the intrinsic conductivity[3]. Loss of water molecules provokes an important decrease in the conductivity values, and the ionic conductivity associated to dehydrated interlayer cations is only appreciated at relatively high temperature, being enhanced by addition of either solid metal salts[4] or certain organic solvents[5].

The ability of montmorillonite to intercalate organic polar molecules $[6,7]$ and some polymeric species[8] is well known. In this way, we have described the intercalation of crown-ethers and poly(ethylene oxide) in homoionic montmorillonites[9-12]. Armstrong et al.[13,14] have studied the influence of some oxyethylene compounds included in PVC matrices in the transport process associated to alkaline ions, in particular by using salts of anions of low mobility. The objective of this work is to study the ionic conductivity of Na-montmorillonite in relation with the intercalation of these oxyethylene compounds, which act as ligands for alkaline interlayer cations. The different strength in

$\ddagger$ Author to whom correspondence should be addressed. the cation-ligands interactions can be of interest in controlling the interlayer ionic mobility.

\section{EXPERIMENTAL}

Montmorillonite from Upton (Wyoming, U.S.A.) was supplied by Ward's Natural Science Establishment Inc. Cation exchange capacity: $91 \mathrm{meq}$ per $100 \mathrm{~g}$. Homoionic samples (Na-montmorillonite) were obtained by treatment with a $1 M$ sodium chloride solution. After complete exchange, the samples were washed and dyalized with distilled water until they were free from chloride ions $\left(\mathrm{AgNO}_{3}\right.$ test).

The polyoxyethylene compounds (cyclic and linear polyethers of general formulae $\left(-\mathrm{CH}_{2}-\mathrm{CH}_{2}-\right.$ $\left.\mathrm{O}-)_{n}\right)(n>3)$, were either macrocyclic crown-ethers or poly(ethylene oxide) with a molecular weight average of $10^{5}$. They were commercial products from Merck: 12-crown-4 (12C4, $n=4), 15$-crown-5 (15C5, $n=5)$, and 18-crown-6 (18C6, $n=6)$, PCR Research Chemical: dibenzo-24-crown-8 (DB24C8, $n=8$ ), and Aldrichs Chemical Company Inc: PEO $\left(n_{\mathrm{ar}}=2275\right)$. The solvents used (Carlo Erba, RPE-ACS grade) were dried under molecular sieves. Na-montmorillonite $(<2 \mu \mathrm{m})$ was intercalated either by treatment of crown-ther solutions in dry methanol, or poly(ethylene oxide) in dry acetonitrile, at $c a 298 \mathrm{~K}$. The resulting products were repeatedly washed with dry solvents, in order to remove physisorbed oxyethylene compounds, and then they were dried under vacuum at about $350 \mathrm{~K}$, until the complete disappearance of the solvents, which was revealed by ir spectroscopy.

The intercalated compounds were characterized by ir spectroscopy (Perkin Elmer 580B double beam spectrophotometer), XRD (Philips PW 1710 instrument with a $\mathrm{Cu}$ anode and $\mathrm{Ni}$ filter), ${ }^{23} \mathrm{Na}$ MAS- 
NMR spectroscopy (Bruker MSL spectrometer; resonance frequency $105.8 \mathrm{MHz}$ ), thermal analysis (TGA, DTG and DTA in a STATON 750 equipment) and elemental analysis (Perkin Elmer 240C microanalyser).

The electrical conductivity was measured in the 298-700 K temperature range under dry nitrogen flow, with a Solartron 1174 FRA connected to a Solartron 1286 electrochemical interface; applied signal amplitude was $100 \mathrm{mV}$ in the nominal frequency range of $0.5 \mathrm{MHz}$ to $10 \mathrm{MHz}$. Circular or rectangular section pellets, pressed at $700 \mathrm{MPa}$, were used for $a c$ measurements perpendicular or parallel to the $(a, b)$ plane of the silicate, respectively.

\section{INTERCALATION COMPOUNDS}

Na-montmorillonite intercalation compounds were obtained and characterized as described in the experimental section. From the results summarized in Table 1, the disposition of ligands are proposed, mainly from the XRD data, showing different values of the interlayer distances $\left(\Delta d_{\mathrm{L}}\right)$ which depends on the nature of the oxyethylene intercalated compound. The compatibility between the cavity size of the crown-ethers and the ionic radius of $\mathrm{Na}^{+}$governs the conformation of the interlayer complexes[9]. So, sodium ions fit well to the cavity of the $15 \mathrm{Cs}$ compound giving a planar disposition with $\Delta d_{\mathrm{L}}=4.1 \AA$, whereas the $18 \mathrm{C} 6$ and DB24C8 exhibiting larger cavities accommodate in different conformations increasing the interlayer distances $\left(\Delta d_{\mathrm{L}}=6.1 \AA\right.$ and $\Delta d_{\mathrm{L}}=8.1 \AA$, respectively). The $12 \mathrm{C} 4$ compound, showing a cavity size smaller than the cationic radius, is able to form $2: 1$ complexes in addition to the corresponding 1:1 stoichiometric complexes (L/C experimental ratio of 1.4, Table 1). In PEO intercalation compounds, the founded interlayer distance $(8 \AA)$ is compatible with a helical structure of the polymer. This situation is supported by additional techniques (ir, NMR) and structural models P. Aranda, unpublished results).
Comparing crown-ether salt complexes formed in solution with the corresponding intercalated compounds obtained by insertion of these macrocyclic polyethers in Na-montmorillonite, it appears that the stoichiometric ratio found for the latter compounds ( $\mathrm{L} / \mathrm{C}$ values in Table 1 ) is less than the ratio established in complexes formed in homogeneous media[15]. In fact, taking into account that each compensating cation $\left(\mathrm{Na}^{+}\right)$disposes of an interlayer area of $73.4 \AA^{2}[16]$ the projection on the $(a, b)$ plane of a polyether intercalated molecule must be equal to or less than this value to produce a complexation able to involve all cations. Steric hindrance may be an important factor determining the $\mathrm{L} / \mathrm{C}$ values which are in general $<1$, indicating that a part of the cations remain uncomplexed $\left(C_{\mathrm{f}}\right.$ in Table 1$)$ whereas the majority of them are associate to the crown-ethers. The $C_{\mathrm{f}}=0$ value found for $12 \mathrm{C4}$ complexes, are explained by the relative small size of this ligand allowing a complete complexation of the $\mathrm{Na}^{+}$ions. In the case of PEO complexes one can suppose that the flexibility of the polymer chain enables a full interaction with the interlayer cations.

\section{IONIC CONDUCTIVITY}

Na-montmorillonite exhibits low ionic conductivity especially after loss of water molecules belonging to the hydration sphere associated with the interlayer cations, in the natural samples. This conductivity is about $10^{3}$ times higher in the parallel direction to the plane defined by the layers than in the perpendicular direction. The anisotropic conductivity is also maintained in the intercalated compounds (Fig 1A). All intercalated materials show higher ionic conductivities than the parent silicate, increasing it with temperature until a maximum value corresponding to a temperature range of $500-600 \mathrm{~K}$. Up to this maximum value, which should depend on the stability of the oxyethylene intercalated complex, the conductivity strongly decreases simultaneously to the progressive decomposition of the intercalated organic

Table 1. Characteristics of the Na-montmorillonite intercalation compounds

\begin{tabular}{cccccc}
\hline sample & $x_{m}(\mathrm{mmol} / 100 \mathrm{~g})$ & $\mathrm{L} / \mathrm{C}$ & $\mathrm{C}_{\mathrm{f}}(\%)$ & $\Delta \mathrm{d}_{\mathrm{L}}(\mathrm{A})$ & disposit. \\
\hline $\mathrm{Na}$-mont/12C4 & 130 & 1.4 & 0 & 8.1 \\
\hline $\mathrm{Na}-\mathrm{mont} / 15 \mathrm{C} 5$ & 69 & 0.8 & 24 & 4.1 \\
\hline $\mathrm{Na}-\mathrm{mon} / 18 \mathrm{C} 6$ & 71 & 0.8 & 22 & 6.1 \\
\hline $\mathrm{Na}$-mont/PEO & 706 & 7.7 & 0 & 0.0 \\
\hline
\end{tabular}

$x_{\mathrm{m}}$ : amount of oxyethylene compound adsorbed.

$\mathrm{L} / \mathrm{C}$ : intracrystalline stoichiometry between oxyethylene ligands $(L)$ and cations (C).

$C_{\mathrm{r}}$ : percentage of free (uncomplexed) cations.

$\Delta d_{\mathrm{L}}$ : interlayer distance. 


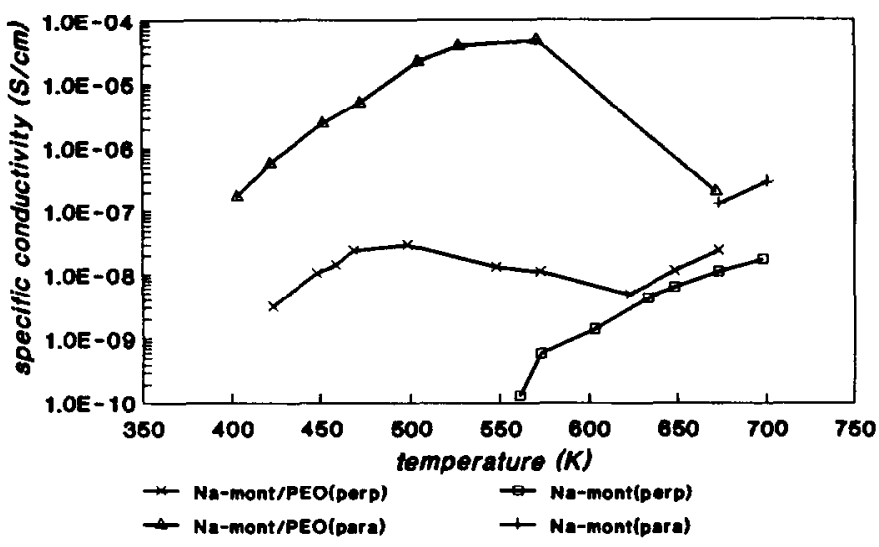

A
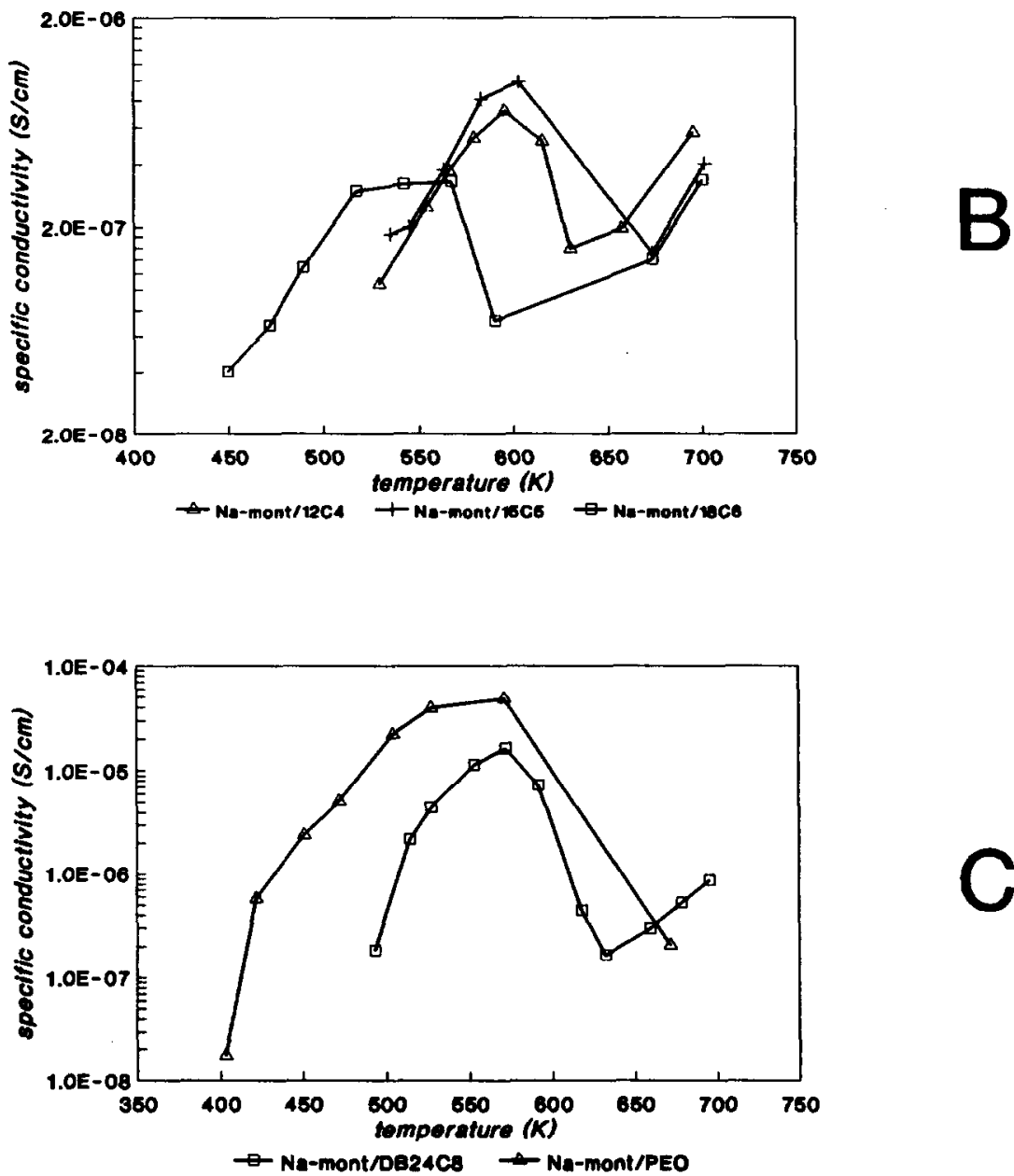

Fig. 1. Specific conductivities as a function of the temperature.

material, reaching the characteristic conductivity of the starting $\mathrm{Na}$-montmorillonite. An example is illustrated in Fig. 1B, where the specific conductivity for $12 \mathrm{C} 4,15 \mathrm{C} 5$ and $18 \mathrm{C} 6$ crown-ethers intercalated into Na-montmorillonite is plotted against the temperature. The conductivity of these intercalation com- pounds depends on the interaction strengths between the interlayer $\mathrm{Na}^{+}$cation and the oxyethylene compound; these macrocyclic polyethers which form very stable complexes restrain the $\mathrm{Na}^{+}$ion-mobility, and consequently the conductivity observed is low (close to $10^{-6} \mathrm{~S} \mathrm{~cm}^{-1}$ in the parallel direction to the layers). 


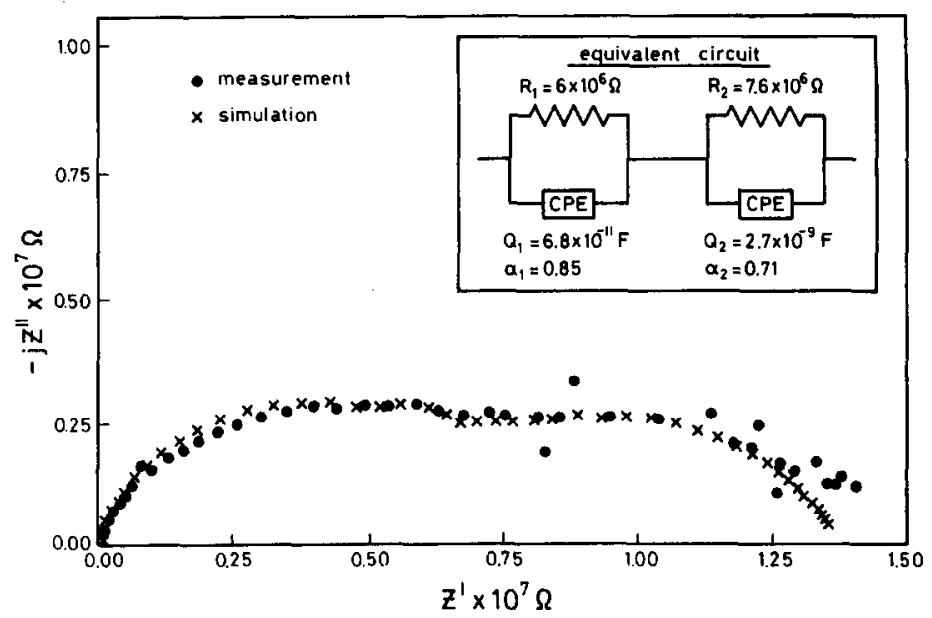

Fig. 2. Nyquist's plot and equivalent circuit proposed for the PEO/Na-montmorillonite compound (ac measurements in parallel direction, at $422 \mathrm{~K}$ ).

On the contrary, either macrocyclic compounds of largest cavities (DB24C8) or poly(ethylene oxide) involve weaker cation-interactions, which can be invoked to explain the significant enhancement of the founded conductivity (Fig. 1C). So, typical values of ionic conductivity in Na-montmorillonite/PEO complexes measured at $570 \mathrm{~K}$ in the parallel direction to the plane $(\mathrm{a}, \mathrm{b})$ of the silicate, are in the $10^{-5}-10^{-4} \mathrm{~S}$ $\mathrm{cm}^{-1}$ range.

We have indicated above the existence of a certain number of uncomplexed $\mathrm{Na}^{+}$ions in some oxyethylene intercalation compounds $\left(c_{\mathrm{f}}\right)$. It may be assumed that these type of cations present a different mobility mechanism than the $\mathrm{Na}^{+}$complexed ions. In this way, Nyquist's plot show in certain cases two semicircles that, in a first attempt, can be interpreted in terms of a physical visualization of the two possible contributions. Thus, Fig. 2 shows a set of ac data, corresponding to the characteristic two semicircle arcs in the complex impedance diagram, for $\mathrm{Ag} / \mathrm{Na}$-montmorillonite $\mathrm{PEO} / \mathrm{Ag}$ cells at $422 \mathrm{~K}$. In this case, all the $\mathrm{Na}^{+}$ions are involved in the interaction with oxyethylene material, and consequently, we can not interpret that behaviour as a conductivity associated to two types of $\mathrm{Na}^{+}$ions. So, a simple $(R C)(R C)$ circuit may give an adequate description of the ac response of these materials. Nevertheless, it is necessary to introduce constant phase elements (CPE) to explain these depressed semicircular arcs[17].

The CPE impedance has the form

$$
Z(\omega)=\mathbf{K}(j \omega)^{-\alpha},
$$

where $\omega$ is the angular frequency, $j=(-1)^{1 / 2}, \alpha$ is a fraction with experimental values of $0.5<\alpha<1.0$, and $K$ is a frequency independent real constant $[17,18]$. In many cases these impedance elements were introduced formally and were only used for fitting impedance data[19]. The physical meaning of $\alpha$ remained unclear, and so $\alpha$ was defined essentially as a fit parameter. Recently, Rammelt and Reinhard[20] related the CPE exponent $\alpha$ to the fractal dimension $D$, a purely geometric quantity, associated to surface inhomogeneity or roughness of solid elec- trodes. The occurrence of the CPE in the case of solid electrodes, and its absence in the case of liquid metal electrodes like mercury with a perfectly smooth surface, suggests that the phenomenon may be due to surface roughness[17, 18].

Figure 2 shows the values obtained for the elements of the equivalent circuit proposed using the Boukamp's simulation system, which correlates the experimental $a c$ data with the corresponding equivalent circuit[21]. The $Q_{1}$ and $Q_{2}$ values may be associated with the bulk and the grain boundary capacitances, respectively[22, 23]. So, in this way the high frequency arc, which passes through the coordinates origin, may be related to the bulk response of the solid material; so, the intercept, $R_{1}$, on the $Z^{\prime}$ axis gives the resistance of the bulk. The second low frequency arc is attributed to a grain boundary impedance in series with the bulk impedance[22]. The value of its capacitance, $Q_{2}$ (calculated from the maximum of the second semicircle), represents charge polarization at the grain boundaries. In the same way the $R_{2}$ values, calculated by extrapolation of this second arc with the real axis, give the grain boundary resistance. Certainly, this point coincides with the sum of $R_{1}$ plus $R_{2}$ and corresponds to the overall resistance of the material.

It is noteworthy that in these materials the contribution of the anions to the conductivity can be considered null, because the negatively charged silicate layers constitute the anionic entities (infinite anionic radii), and consequently the transport cationic number $\left(t_{+}\right)$for these systems must be assumed to be unity, in view of the immobility of the anions. This situation is quite different to conventional PEO-salt complexes where an organic macromolecule acts as a solvent of the salt and dissociates partially, making it possible for the system to operate as a mixed cationic/anionic ion-conductor. Thus in the present intercalated materials exclusively cationic conductivity takes place.

Acknowledgements-Financial support from the Fundación Ramón Areces and from the CICYT, Spain, is gratefully acknowledged. 


\section{REFERENCES}

I. J. J. Fripiat, A. Jelli, G. Poncelet and J. André, J. phys. Chem. 69, 2185 (1965).

2. R. Calvet and J. Mamy, C.r. Acad. Sci. Paris 273, 1251 (1971).

3. R. C. T. Slade, J. Barker, P. R. Hirst and T. K. Halstead, Solid St. Ionics 24, 289 (1987).

4. T. Kawada, H. Tokokawa and M. Dokiya, Solid St. Ionics 28-30, 210 (1988).

5. W. L. Wang and F. L. Lin, Solid St. Ionics 40-41, 125 (1990).

6. B. K. G. Theng, The Chemistry of Clay-Organic Reactions (Edited by Adam Hilger). London (1974).

7. J. A. Rausell-Colom and J. M. Serratosa, in Chemistry of Clays and Clay Minerals (Edited by A. C. D. Newman). London (1987).

8. B. K. G. Theng, Formation and Properties of Clay-Polymer Complexes. Elsevier Science, Amsterdam (1979).

9. E. Ruiz-Hitzky and B. Casal, Nature 276, 596 (1978).

10. E. Rviz-Hitzky and B. Casal, Chemical Reactions in Organic and Inorganic Constrained Systems (Edited by R. Setton), p. 179. Reydel, Dordrecht (1986).

11. B. Casal and E. Ruiz-Hitzky, Clay Min. 21, 1 (1986).
12. E. Ruiz-Hitzky and P. Aranda, Adv. Mater, 2, 545 (1990).

13. R. D. Armstrong, J. M. Handyside and B. W. Johnson, Corr. Sci. 30, 569 (1990).

14. R. D. Armstrong and G. Horvai, Electrochim. Acta 35, 1 (1990).

15. R. M. Izatt, J. S. Bradshaw, S. A. Nielsen, J. D. Lamb and J. J. Christensen, Chem. Rev. 85, 271 (1985).

16. H. Van Olphen, An Introduction to Clay Colloid Chemistry, 2nd Edn. John Wiley \& Sons, New York (1977).

17. W. H. Mulder and J. H. Sluyters, Electrochim. Acta 33, 333 (1988).

18. L. Nyikos and T. Pajkossy, Electrochim. Acta 30, 1533 (1985).

19. M. Kending, E. M. Meyer, G. Lindberg and F. Mansfeld, Corr. Sci. 23, 1007 (1983)

20. U. Rammelt and G. Reinhard, Electrochim. Acta 35, 1045 (1990)

21. B. A. Boukamp, Equivalent Circuit. Users Manual, 2nd Edn. University of Twente, Report CT89/214/128, Enschede (1989).

22. P. G. Bruce and A. R. West, J. electrochem. Soc. 130, 662 (1983).

23. J. T. S. Irvine, D. C. Sinclair and A. R. West, Adv. Mater. 2, 132 (1990). 